\title{
The endocrine influence on the bone microenvironment in early breast cancer
}

\author{
Caroline Wilson', Hannah Brown² and Ingunn Holen²
}

${ }^{1}$ Academic Unit of Clinical Oncology, Weston Park Hospital, University of Sheffield, Sheffield, UK 2Department of Oncology and Metabolism, University of Sheffield, Sheffield, UK
Correspondence should be addressed to $C$ Wilson

Email

c.wilson@sheffield.ac.uk

\begin{abstract}
Multiple factors influence the survival of disseminated breast tumour cells (DTCs) in bone. Whereas gene signature studies have identified genes that predict a propensity of tumours to metastasise to bone, the bone environment is key in determining the fate of these tumour cells. Breast cancer cells locate to specific niches within the bone that support their survival, regulated by host factors within the bone microenvironment including bone cells, cells of the bone micro vasculature, immune cells and the extracellular matrix. Reproductive endocrine hormones that affect bone and clinical studies across the menopausal transition have provided comprehensive understanding of the changes in the bone microenvironment during this time. Menopause is characterized by a decrease in ovarian oestradiol and inhibins, with an increase in pituitary follicle-stimulating hormone and this review will focus on the role of these three hormones in determining the fate of DTCs in bone. Both in vivo and clinical data suggest that premenopausal bone is a conducive environment for growth of breast cancer cells in bone. Adjuvant cancer treatment aims to reduce the risk of tumour recurrence by affecting DTCs. Drugs targeting the bone resorbing osteoclasts, such as bisphosphonates, have therefore been evaluated in this setting. Both preclinical and adjuvant clinical studies have shown that bisphosphonates' ability to decrease tumour growth in bone is influenced by the levels of endocrine hormones, with enhanced effects in a postmenopausal bone microenvironment. The challenge is to understand the molecular mechanisms behind this phenomenon and to evaluate if alternative adjuvant bone-targeted therapies may be effective in premenopausal women.
\end{abstract}

\section{Key Words}

- breast cancer

- bone microenvironment

- bisphosphonates

- reproductive hormones

\section{Introduction}

The process of metastatic spread of the primary breast tumour to bone is undoubtedly inefficient, with less than $0.01 \%$ of tumour cells released into the circulation able to form bone metastases (Cameron et al. 2000). Multiple factors influence the success or failure of these tumour cells, including their intrinsic properties and the myriad of environmental factors encountered
Endocrine-Related Cancer (2016) 23, R567-R576 on the transit from breast to bone. Gene signature studies have identified genes that predict a propensity of tumours to metastasise to bone, including CAPG, GIPC1 and TFF1 (Smid et al. 2006, Westbrook et al. 2016), but whilst these have a predictive value they cannot determine bone-related disease outcomes for individual patients and are therefore not yet used in the 
clinical setting. The environment plays an important role in determining the fate of tumour cells; they have to overcome shear forces and oxidative stress in the circulation before extravasating (Massague \& Obenauf 2016), once in the bone microenvironment they are vulnerable to immune surveillance. There is evidence that breast cancer cells locate to specific niches within the bone microenvironment that will support their survival, using chemokine receptors such as CXCR4 to select for areas of ligand (CXCL12, also known as SDF-1)rich bone marrow (Muller et al. 2001). Tumour cells secrete various factors to modify this new environment and promote their survival, supporting dormancy and recurrence years after the primary tumour (Kang \& Pantel 2013). Adjuvant therapy after removal of the primary breast tumour aims to reduce the risk of tumour recurrence by targeting single-cell/smallvolume micrometastases that have not yet acquired the ability to sustain autonomous growth. However, it is now recognized that these small-volume disseminated tumour cells (DTCs) may be in a non-proliferative state and not responsive to anti-proliferative agents (Massague \& Obenauf 2016). There is, therefore, a need for alternative therapies that target DTCs to either initiate or maintain them in a dormant state, or that modify the microenvironment to make it less hospitable and thereby promote tumour cell death. The bonetargeting bisphosphonates have been evaluated in large phase III adjuvant breast cancer trials, and trials are ongoing with the newer agent denosumab. Both types of agents target the bone-resorbing osteoclast (Oc). The bisphosphonate trials showed an interesting interplay between the prevailing endocrine environment and the efficacy of bisphosphonates; only women with postmenopausal levels of ovarian hormones (natural or chemically induced with the ovarian suppressor goserelin) showed improvements in disease outcomes with addition of bisphosphonates to standard adjuvant therapy (Coleman et al. 2015). This suggests that the endocrine influence on bone creates two distinct bone microenvironments (pre- vs postmenopausal) that differentially affect DTCs within them and influence therapies that target the bone-resorbing Ocs.

\section{Tumour dissemination to bone and the bone microenvironment}

Bone metastases from breast cancer are currently incurable with a median survival of 2.3 years following diagnosis (Harries et al. 2014). The formation of clinically evident bone metastases represents the final part of a process of interactions between tumour cells and bone cells that may have lasted for decades in patients who experience disease relapse many years after surgical excision of their primary tumour. DTCs are found in the bone marrow of a third of patients and $50 \%$ of these will develop metastatic disease during the first 10 years post diagnosis (Braun et al. 2005). Thus, the presence of DTCs confers a poorer prognosis, but there is also a significant proportion of patients in whom tumour cells reach the bone marrow but do not develop into metastases; hence, DTCs either die or are maintained in a state of dormancy. When DTCs arrive in bone they interact with the host cells, including vessels, osteoblasts and osteoclasts, in a putative metastatic niche. The bone-forming osteoblasts (Ob) are derived from mesenchymal progenitor cells and lay down new unmineralized matrix in the resorption pits formed by the bone-resorbing osteoclasts. The presence of tumour cells alters the bone microenvironment, increasing numbers/activity of Oc and decreasing the numbers/activity of $\mathrm{Ob}$, even before the development of overt bone lesions (Brown et al. 2012). These early interactions may influence the outcome for tumour cells, determining whether they die, enter a dormant non-proliferative state or undergo early expansion to macrometastases. It is now well recognized that tumour cell fate can be influenced by multiple host factors within the bone microenvironment (Fig. 1).

\section{Osteoblasts and haematopoetic stem cells (HSCs)}

In normal physiology HSCs contribute to haematopoesis for months or even a lifetime. They respond to extrinsic (microenvironmental) signals to remain quiescent, to self-renew or to undergo differentiation. The dormant state may in part be controlled by the $\mathrm{Ob}$ with evidence that increasing the number of Obs with parathyroid hormone (PTH) also increases the number of HSCs and the number of DTCs from subcutaneous prostate tumours (Shiozawa et al. 2011). These DTCs are thought to be subject to the same Ob-derived signals that maintain HSC dormancy, thus maintaining tumour cell survival and contributing to relapse in bone many years after the initial diagnosis of the primary tumour. A recent study in mice has demonstrated that breast cancer cells form heterotypic adherence junctions with osteoblastic cells, resulting in activation of mTOR in the tumour cells and their proliferation to form micrometastases, implicating the osteoblasts in early progression (Wang et al. 2015).

Published by Bioscientifica Ltd 

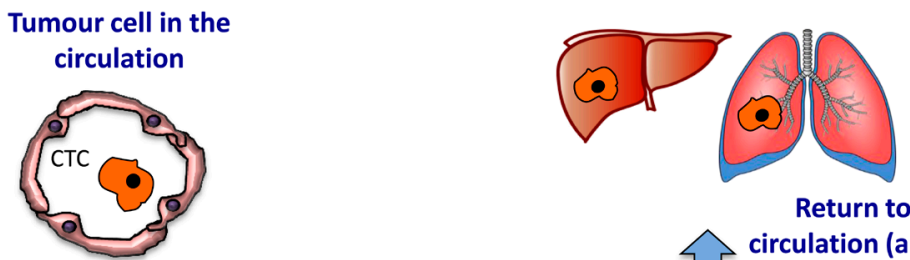

Return to the circulation (and seed

Home to bone niche(s)
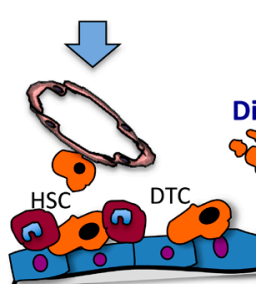

Die? Stay dormant? to other organs)?

\begin{tabular}{|cccl|}
\hline Hormone & $\begin{array}{c}\text { Change in serum levels } \\
\text { with menopause }\end{array}$ & Effect on bone cells & Effect on tumour cells in bone \\
\hline Oestradiol & Decrease & - Oc & $\begin{array}{l}\text { Promotes spread and growth of ER-positive breast } \\
\text { cancer cells to bone but not ER-negative (Holen et al. } \\
\text { 2016) }\end{array}$ \\
\hline Inhibins & Decrease & - Ob & $\begin{array}{l}\text { Inhibin A does not affect spread of ER-negative cells to } \\
\text { bone (Wilson et al. 2016). Effects on growth in bone not } \\
\text { defined. }\end{array}$ \\
\hline $\begin{array}{c}\text { Follicle stimulating } \\
\text { hormone }\end{array}$ & Increase & + Ob & $\begin{array}{l}\text { Oc (+ Oc in vivo) } \\
\text { not defined. }\end{array}$ \\
\hline Prolactin & Decrease & - Ob & $\begin{array}{l}\text { Prolactin induces breast cancer cell secretion of } \\
\text { osteolytic factors (Sutherland et al. 2015). Effects on spread } \\
\text { and growth of cancer cells in bone not defined. }\end{array}$ \\
\hline
\end{tabular}

Figure 1

Tumour cell interactions with the bone microenvironment and the effect of endocrine hormones. Tumour cells home to vascular areas within bone interact with bone cells and can enter a state of dormancy/quiescence for many years before growth. They are in close contact with bone and are thought to occupy the HSC niches. Following unknown triggers, the tumour cells regain the ability to proliferate and ultimately form bone metastases or spread to other metastatic sites. The table provides a brief overview of the influence of endocrine hormones on bone cells involved in the metastatic niche.

\section{Osteoclasts}

These bone-resorbing cells are activated by various factors produced by tumour cells in bone, including receptor activator of nuclear factor- $\mathrm{B}$ (RANK) ligand, PTH-related protein (PTHrP), interleukins 1 and 6, and macrophage inflammatory protein-1-alpha (Roodman 2001). The activation of Oc induces bone resorption and release of tumour growth factors from the bone matrix including TGF $\beta$, BMPs, calcium, PDGF and IGF that promote tumour growth and expansion in bone. The activity of Oc is tightly controlled under normal physiological circumstances and is coupled with the activity of Ob through coupling mechanisms such as the RANKL-RANK interaction; Obs produce RANKL to activate Ocs in addition to the soluble decoy receptor for RANKL, osteoprotegerin (OPG), which inhibits Oc development (Cross et al. 2006). OPG is also secreted by numerous breast cancer cells and its expression decreases with increase in tumour grades
(Holen et al. 2005). Although established as the main driver of cancer-induced bone disease, the precise role of the Oc in the early stages of tumour cell dissemination to bone remains to be determined. Interestingly, Ocs appear to be dispensable for haematopoietic stem cell maintenance and mobilization (Miyamoto et al. 2011), whereas Oc activity triggers growth of DTCs to form overt metastases (Ottewell et al. 2014, 2015). These data suggest that different cell populations residing in bone marrow niches have differential interactions, potentially regulated by distinct signalling pathways.

\section{Bone microvasculature}

Blood vessels within the bone express adhesion proteins including P-selectin and E-selectin that are able to act as anchors for tumour cells (Nguyen et al. 2009) and the highly fenestrated endothelial cell layer of blood vessels

Published by Bioscientifica Ltd 
in bone promotes the extravasation of circulating tumour cells out of circulation and into bone (Mastro et al. 2003). Once in bone, tumour cells are located in close proximity to blood vessels (Fig. 2) and endothelial cells of the mature microvasculature have been shown to promote tumour cell dormancy through secretion of thrombospondin 1 (Ghajar et al. 2013). Dormancy is also maintained by the secretion of anti-stromal-derived growth factor-1 (SDF-1) micro-RNAs (miRNAs) from either endothelial cells or other stromal cells within close proximity to blood vessels. These anti-SDF1 miRNAs (miR-127, -197, -222 , and -223) are transferred to the tumour cells by gap junctions and induce tumour cell growth arrest (Lim et al. 2011). miRNAs play further roles in metastases and silencing of miRNA-126 expression in breast cancer cells increased metastases to multiple sites including bone by promoting endothelial cell recruitment to breast cancer cells (Png et al. 2012).

\section{Inflammatory and immune cells}

Macrophages within tumours possess dual roles: some have a tumour growth-suppressive action (M1) and some a growth-promoting action on both tumours and blood vessels (M2). Tumour-associated macrophages (TAMs) are also able to limit the effect of anti-cancer therapies by associating with tumour blood vessels and promoting revascularization after chemotherapy in both primary breast tumours and bone metastases (Hughes et al. 2015). In this study, TAMS were attracted to these sites by the interaction of tumour expressed CXCL12 and TAM expressed CXCR4. Bone contains a plethora of inflammatory cells that can influence tumour cell homing and survival in bone including myeloid cells which express integrin $\alpha 4 \beta 1$ and facilitate tumour cell homing to bone (Papayannopoulou et al. 2001). Both tumour cells and associated myeloid cells produce inflammatory cytokines, including interleukins $1 \beta$ and 6, TNF $\alpha$ (Kinder et al. 2008), which induce $\mathrm{Ob}$ and bone stromal cells to secrete factors which attract more myeloid cells and perpetuate the protumourigenic effects by stimulating RANKL expression on $\mathrm{Ob}$ (Lam et al. 2000), which activates Oc and promotes the 'vicious cycle' of bone metastases. In addition, PTHrP secreted from breast cancer cells induces IL- 6 and VEGF-A expression in $\mathrm{Ob}$, which enhances angiogenesis and induces expression of matrix remodelling proteases that support tumour growth in bone (Park et al. 2013).

\section{Extracellular matrix and tumour hypoxia}

Breast cancer cells that are cultured in vitro with mesenchymal stem cells demonstrate upregulation of lysyl oxidase (LOX), an enzyme that catalyses crosslinking between collagens and elastins in the extracellular matrix. LOX changes the behaviour of the cancer cells from an epithelial to a more invasive mesenchymal phenotype, which may promote the spread of these cells to the bone (El-Haibi et al. 2012). In a cohort of patients with oestrogen receptor negative (ER-) breast cancers, primary tumours that showed upregulation of

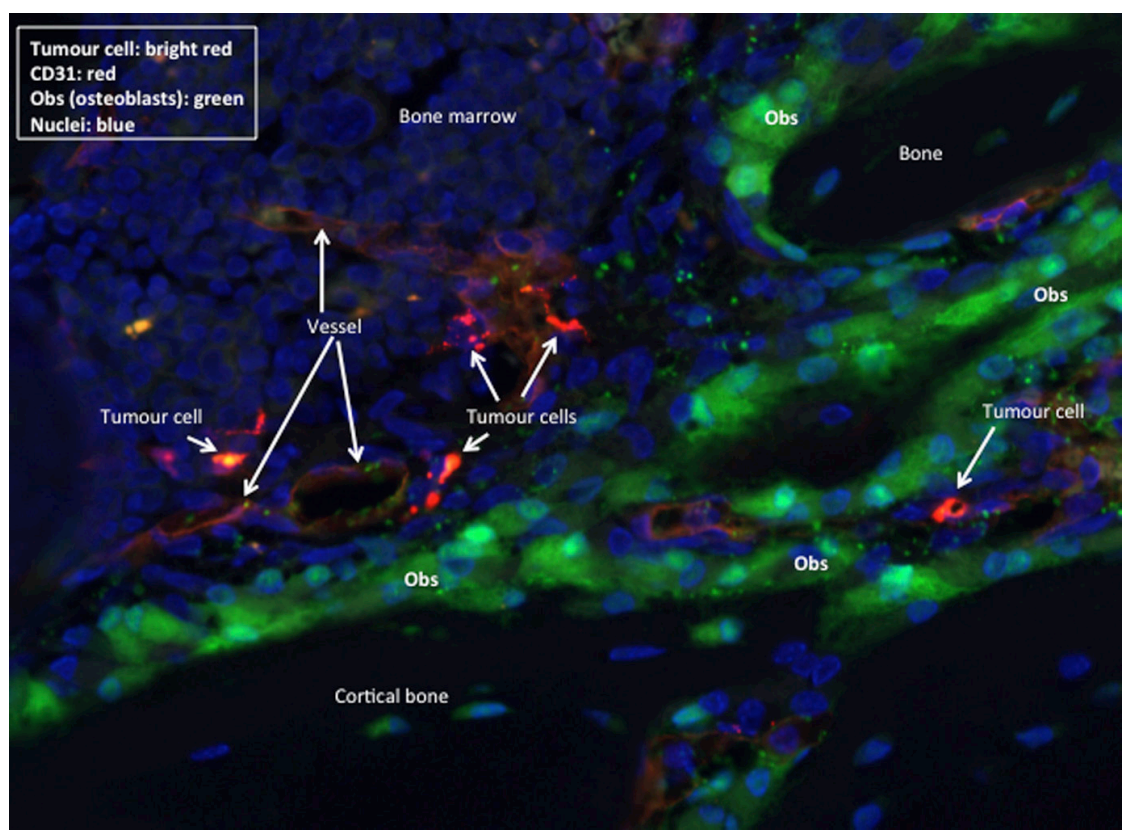

Figure 2

Breast tumour cells visualized in close proximity to osteoblasts and blood vessels in mouse bone. Genetically engineered mice with GFP-expressing osteoblasts injected via the intracardiac route with CMDii-labelled human MDA-MB-231 cells before sample collection and processing for paraffin sections. Histological sections of tibias were stained with markers for endothelial cells using antibodies and DNA was visualized using DAPI. Tumour cells, osteoblasts and blood vessels were seen in close proximity to each other within the bone marrow compartment. 
genes involved in tumour hypoxia, including LOX, was associated with metastases to bone rather than lung, liver and brain (Cox et al. 2015), suggesting that LOX may be involved in preferential homing of tumour cells to bone. A murine model of spontaneous ER-ve breast cancers that express LOX showed that the appearance of focal osteolytic lesions preceded the arrival of tumour cells in bone, suggesting that hypoxia-induced tumour secreted factors, including LOX, 'primes' the bone to receive tumour cells through an increase in Oc-mediated bone resorption (Cox et al. 2015). Numerous additional extracellular matrix molecules are involved in the formation of a pre-metastatic niche, including periostin (Wang et al. 2016), tenascin (Chiovaro et al. 2015) and thrombospondin (Ghajar et al. 2013) but how their levels/activity are affected by endocrine hormones remain largely unexplored. Another component of the extracellular matrix are cancer-associated fibroblasts (CAF), which promote tumour growth and angiogenesis in breast cancer cells through recruitment of bone marrow-derived endothelial cells through production of SDF-1 (Orimo et al. 2005).

\section{Endocrine effects in bone}

The effects of endocrine hormones on bone are numerous and clinical studies across the menopausal transition have provided comprehensive understanding of the changes in the bone microenvironment during this time (Perrien et al. 2006). As menopause is characterized by a decrease in ovarian oestradiol and inhibins, with an increase in pituitary follicle-stimulating hormone (FSH), this review will focus on the role of these three key hormones. The role of other hormones may also be important, with a recent study reporting a role for prolactin in the development of breast cancer bone metastasis and the associated bone disease (Sutherland et al. 2015). Prolactin has been shown to enhance bone turnover (Seriwatanachai et al. 2008), however levels decrease during menopause (Tanner et al. 2011) and whether bone-targeted agents directly influence prolactin levels remain to be determined.

Oestrogen has a well-documented effect on osteoblasts and osteoclasts as both cell types express oestrogen receptors (ER) $\alpha$ and $\beta$. Oestrogen exerts its effect on bone cells by direct inhibition of osteoclastogenesis, promotes Ob-mediated bone formation, in addition to inhibiting $\mathrm{Ob}$ production of osteoclastic cytokines such as TGF $\beta$ (Krassas \& Papadopoulou 2001). Oestrogen also maintains the number and activity of HSCs in bone (Qiu et al. 2012), and increases the ratio of OPG/RANKL (Yan \& Ye 2015).
The ability of oestrogen to affect the bone vasculature is not well described, but there is close association between osteogenesis and vasculogenesis suggesting that modification of bone will influence vessels and vice versa. $17 \beta$-Oestradiol can influence subcutaneous tumour vasculature, increasing vessel density and maintaining a more structured vasculature (Pequeux et al. 2012). The immune system can be modified by oestrogen with evidence that oestrogen inhibits the secretion of pro-inflammatory cytokines including IL- $6, \mathrm{TNF} \alpha$ and macrophage inhibitory factor from monocytes mediated through the ER $\alpha 36$ receptor on the surface of human peripheral monocyte (Pelekanou et al. 2016). Oestrogen also affects miRNA expression and CAFs with evidence that $17 \beta$-estradiol induces miR144 expression resulting in downregulation of the onco-suppressor Runx1 (Vivacqua et al. 2015).

Inhibins are not abundantly expressed in bone, but radiolabelled inhibin A administered intravenously in vivo accumulates rapidly in the bone marrow (reviewed in Wilson et al. 2012). Its effects on bone turnover was highlighted in a cross-sectional study of women aged 21-85 $(n=188)$, where endocrine hormones were correlated to changes in serum markers of bone formation, bonespecific alkaline phosphatase (BSAP) and bone resorption, carboxyterminal telopeptide of type I collagen (CTX). Inhibin $\mathrm{A}$ was the most accurate predictor of changes in bone formation and resorption being negatively correlated with levels of BSAP and CTX (Perrien et al. 2006), thus declining inhibins in early menopause will lead to increased bone turnover. Inhibins also influence both the adaptive and innate immune systems, affecting the development and function of immune cells (AlemanMuench \& Soldevila 2012). The specific effects of inhibin on the immune system within bone has not been defined; however, inhibins do not have an identified downstream signalling pathway but instead bring about their effector functions by binding to the activin receptor (ACTRIIA) and inhibiting the biological actions of activin (Jeruss et al. 2003). Activin, secreted from monocytes and bone fibroblasts, has been shown to suppress immune processes in bone (Abe et al. 2002), suggesting the inhibin/activin pathway may be important for bone-specific immune/ inflammatory processes.

Inhibins inhibit the secretion of FSH from the anterior pituitary. In the cross-sectional study discussed previously, FSH correlated with bone resorption markers (CTX) but not bone formation markers (BSAP) in perimenopausal women only (Perrien et al. 2006). In vivo treatment of ovariectomized 14-week old mice with an antibody to

Published by Bioscientifica Ltd 
$\beta$-subunit of FSH prevented OVX-induced bone loss after 4 weeks of treatment associated with increases in bone formation and inhibition of bone resorption (Zhu et al. 2012). There is, however, reports suggesting that lowering FSH increases bone resorption; a prospective study of changes in bone turnover in postmenopausal women $(n=46)$ with inhibition of FSH, using GnRH agonists, showed a significant increase in CTX and TRAP5b (serum markers of bone resorption) with suppression of FSH, in addition to a significant increase in P1NP (a marker of bone formation) (Drake et al. 2010). Thus, the specific effects of FSH on bone turnover still need to be defined. FSH has effects on HSC in bone, with evidence from in vivo models that bone-derived HSC express FSH receptor and that treatment with FSH enhances haematopoetic recovery after chemotherapy (Shaikh et al. 2016). FSH also influences the vasculature; the FSH receptor (not normally expressed on vascular endothelium) is upregulated in the vasculature of bone metastases (Siraj et al. 2013). The influence of FSH on bone mass has also been linked to its effects on the immune system; production of boneresorbing cytokines and bone mineral density (BMD) was evaluated in 36 healthy women (aged 20-50) and showed BMD was inversely proportional to FSH levels and endogenous FSH levels correlated with circulating levels of IL-1beta. Moreover, exogenous FSH induced isolated monocytes to secrete IL-1beta, TNF-alpha and IL-6 (Cannon et al. 2010).

These data show that the endocrine hormones oestrogen, inhibin and FSH can modify multiple components resulting in very different bone microenvironments in pre- and postmenopausal women. At the time of the final menstrual period, the majority of women will have undetectable levels of inhibins (Burger et al. 2002); however, oestradiol remains detectable in serum for up to 5 years (Burger et al. 1999). The rise in FSH can occur up to 3-10 years before menopausal transition (Burger et al. 2007), attributed to the decline in inhibins (Klein et al. 2004). The differing levels of endocrine hormones in pre- and postmenopausal women will therefore exert differential effects on DTCs in bone, with the potential to modify both tumour growth and response to bone-targeted therapy.

\section{Endocrine effects on tumour cells in bone}

In vivo the influence of endocrine hormones within the bone microenvironment in regulating the fate of DTCs has been described. A 12-week-old BALB/c nude mice underwent ovariectomy (OVX) and the bone microenvironment evaluated. Within 2 weeks post procedure the bone microenvironment of OVX animals was significantly altered compared with sham animals with an increase in Oc activity and decrease in Ob activity (Ottewell et al. 2014). This alteration in the bone microenvironment affected breast tumour cell homing to bone following intracardiac (IC) injection of MDA-MB-231 cells 7 days post OVX, with significantly higher numbers of tumour cells in bone of control compared with OVX animals. However, at a later time tumour growth in bone was detected in $18 \%$ of sham animals and $89 \%$ of OVX animals indicating that whilst OVX bone may be less attractive for tumour cell homing, it is more conducive to survival and growth of cells that do colonize bone (Ottewell et al. 2014). This data is supported by the results from clinical studies evaluating disease recurrence in patients following a diagnosis of breast cancer. Combined data on the incidence of bone marrow micrometastases in over 4000 women showed that premenopausal women had significantly higher incidence of bone marrow micrometastases than postmenopausal women $(32.7 \%$ vs $29.5 \% \quad P \leq 0.001)$ (Braun et al. 2005), indicating that premenopausal bone offers more favourable conditions for DTCs. A further study evaluating the incidence of clinically overt bone metastases in over 7064 women showed the incidence to be significantly higher in younger women (Harries et al. 2014) suggesting that premenopausal bone can support the growth of DTCs into bone metastases. Further data on recurrence patterns of 6792 breast cancer patients entered into trials conducted by the International Breast Cancer Study Group showed that younger patients ( $<35$ years) had significantly higher incidences of bone metastases occurring during the course of their disease (Colleoni et al. 2000). These data suggest that younger women may be at increased risk for bone metastases but how and which endocrine hormone is affecting the bone microenvironment and DTCs is yet to be defined.

\section{Endocrine influence on bone-targeted therapies}

Both preclinical and clinical studies have found that the anti-tumour efficacy of osteoclast-targeted agents is influenced by levels of endocrine hormones, with differential effects according to menopausal status. These bone-targeted therapies have included bisphosphonates, the RANKL inhibitor denosumab and the soluble decoy receptor OPG-Fc.

Published by Bioscientifica Ltd 
In vivo studies have shown that tumour growth in bone of 12-week-old BALBc/nude mice injected IC with the breast cancer cell line MDA-MB-231 was significantly decreased with zoledronic acid (Zol) in animals who had undergone OVX (modelling postmenopausal) but not sham-OVX (modelling premenopausal) (33\% vs $86 \%$ ). This effect on tumour cells was independent of the effect of Zol on bone volume with drug-induced increases in both groups and no significant difference in bone volume between Zol-treated groups (Ottewell et al. 2014). This indicates that the effect of Zol on formation of bone metastases is independent of bone volume but dependent upon other factors in the bone microenvironment that are differentially affected by Zol according to the prevailing level of endocrine hormones. Further in vivo data has supported an Oc-mediated differential effect on breast cancer bone metastases according to menopausal status using the potent inhibitor of osteoclastogenesis, OPG-Fc, which prevents Oc activation by preventing RANKL-RANK binding similar in mechanism to denosumab (Ottewell et al. 2015). OPG-Fc increased bone volume in 12-weekold BALBc/nude mice post OVX and reduced number and activity of both Oc and Ob. Tumour growth in bones after IC injection of MDA-MB-231 cells was decreased by OPG-Fc in OVX animals (7\% vs $78.5 \%$ ) but no effect was seen in sham-OVX animals. These data suggest that pharmacological inhibition of Ocs decreases breast tumour growth in bones but only in a bone microenvironment that mimics postmenopausal (OVX) with low levels of oestradiol and inhibin and high levels of FSH.

Clinical studies of adjuvant bisphosphonates for early breast cancer have included thousands of patients treated with both oral and intravenous bisphosphonates. The largest of the zoledronic acid studies included AZURE $(n=3340)$ (Coleman et al. 2011), ABCSG-12 $(n=1803)$ (Gnant et al. 2011) and ZO-FAST ( $n=1065)$ (Coleman et al. 2013). AZURE recruited patients with a mixed menopausal status; premenopausal (45\%), unknown menopausal status $(9.7 \%),<5$ years since menopause (14.7) and $>5$ years since menopause (31\%). Patients were randomized to receive standard adjuvant therapy \pm zoledronic acid for 5 years and the primary endpoint was disease-free survival (DFS). Patients who were $>5$ years postmenopausal showed a significantly improved DFS with the addition of zoledronic acid (ZOL) to standard therapy (ST) (DFS; ST $71 \%$, ST+ZOL $78.2 \%$, HR $0.75,95 \%$ CI $0.59-0.96$ $P=0.02$ ), but this effect was not seen in any other patient groups. ABCSG-12 recruited premenopausal women that all received the goserelin, which induced a chemical menopause, before being randomized to receive tamoxifen/anastrazole \pm zoledronic acid every 6 months for 3 years. The primary endpoints were DFS and zoledronic acid significantly improved DFS compared with endocrine therapy alone ( $92 \%$ vs $88 \% P=0.008$ ). A preplanned subgroup analysis according to age demonstrated a significant beneficial effect of zoledronic acid on DFS in women $>40$ years (HR $0.58,95 \%$ CI $0.4-0.83$ ), and these effects were not seen in women $<40$ years (HR $0.94,95 \%$ CI 0.57-1.56), which may be due to incomplete ovarian suppression by goserelin in very young women. ZO-FAST evaluated addition of zoledronic acid to the aromatase inhibitor letrozole for 5 years in postmenopausal women with zoledronic acid initiated either at the start of the letrozole (early) or delayed until evidence of BMD loss or fracture. The primary endpoint of this study was change in BMD at 12 months but pre-planned secondary analyses included DFS and OS. Patients who started zoledronic acid with letrozole had a 34\% decrease in DFS events (HR 0.66 95\% CI 0.44-0.97 $P=0.0375$ ) and exploratory analyses according to menopausal status at randomization showed that women $>5$ years postmenopausal or $>60$ years has a substantially improved OS with early versus delayed zoledronic acid (HR 0.5; $P=0.0224$ ). This effect was not seen in women who were recently postmenopausal due to chemotherapy-induced ovarian toxicity, oophorectomy or ovarian suppression. These trials indicated that adjuvant zoledronic acid was able to improve disease outcomes only when started in women who had a very suppressed hypothalamic-pituitary-gonadal (HPG) axis either naturally or chemically. Similar results were reported with the adjuvant clodronate trials (Powles et al. 2006, Paterson et al. 2012) and a large meta-analysis of all adjuvant bisphosphonate trials involving $>18,000$ breast cancer patients has recently reported and showed that women who were postmenopausal at initiation of bisphosphonates had fewer recurrences in bone (RR 0.72, $0.60-0.86 ; 2 P=0.0002$ ), at other distant sites (RR 0.82, $0.74-0.92 ; 2 P=0.0003)$ and an improved breast cancer mortality (RR 0.82, 0.73-0.93; $2 P=0.002$ ) (Coleman et al. 2015). Inhibiting Ocs by inhibiting the RANKL-RANK interaction is currently being evaluated in phase III trials of the RANK ligand inhibitor denosumab and recent data from the ABCSG-18 trial has shown that adjuvant denosumab reduces the risk of disease recurrence in postmenopausal patients with early stage hormone receptor positive breast cancer (Gnant et al. 2015), suggesting that osteoclast inhibition with an alternative pharmacological agent to bisphosphonates also improves outcomes in patients with a quiescent HPG axis. Further data is awaited from the D care study, which is a phase III

Published by Bioscientifica Ltd. 
trial evaluating addition of denosumab to standard adjuvant therapy for 5 years in pre- and postmenopausal women to define the population of patients who will derive most benefit.

\section{Summary}

It is evident that endocrine hormones play a key role in modifying multiple cells within the bone microenvironment, including bone cells, immune cells, stromal cells and the vasculature, as well as systemic factors and extracellular matrix components (Holen 2016). This plethora of cellular effects will undoubtedly have an influence on the homing to and survival of DTCs within the bone microenvironment, with evidence to suggest that this process is enhanced in a premenopausal bone microenvironment with high oestradiol and inhibin and low FSH. The clinical utility of Oc inhibitors, used in early breast cancer, with the aim to prevent bone metastases and improve disease outcomes (DFS and OS) has been confirmed in a meta-analysis of large phase III clinical trials involving thousands of women (Coleman et al. 2015). These trials have shown that inhibition of the Oc is only effective in preventing metastases when there is a suppressed HPG axis, due to either natural menopause or chemically induced with GnRH analogues. The challenge now is to understand the molecular mechanisms behind this phenomenon and to evaluate if alternative bone-targeted therapies, which act on other cellular components of the bone microenvironment, may be effective in premenopausal women where there is a clear need for bone-targeted adjuvant therapy.

\section{Declaration of interest}

The authors declare that there is no conflict of interest that could be perceived as prejudicing the impartiality of this review.

\section{Funding}

This research did not receive any specific grant from any funding agency in the public, commercial or not-for-profit sector.

\section{References}

Abe M, Shintani Y, Eto Y, Harada K, Kosaka M \& Matsumoto T 2002 Potent induction of activin A secretion from monocytes and bone marrow stromal fibroblasts by cognate interaction with activated $\mathrm{T}$ cells. Journal of Leukocyte Biology 72 347-352.

Aleman-Muench GR \& Soldevila G 2012 When versatility matters: activins/inhibins as key regulators of immunity. Immunology and Cell Biology 90 137-148. (doi:10.1038/icb.2011.32)
Braun S, Vogl FD, Naume B, Janni W, Osborne MP, Coombes RC, Schlimok G, Diel IJ, Gerber B, Gebauer G, et al. 2005 A pooled analysis of bone marrow micrometastasis in breast cancer. New England Journal of Medicine 353 793-802. (doi:10.1056/ NEJMoa050434)

Brown HK, Ottewell PD, Evans CA \& Holen I 2012 Location matters: osteoblast and osteoclast distribution is modified by the presence and proximity to breast cancer cells in vivo. Clinical and Experimental Metastasis 29 927-938. (doi:10.1007/s10585-012-9481-5)

Burger HG, Dudley EC, Hopper JL, Groome N, Guthrie JR, Green A \& Dennerstein L 1999 Prospectively measured levels of serum follicle-stimulating hormone, estradiol, and the dimeric inhibins during the menopausal transition in a population-based cohort of women. Journal of Clinical Endocrinology and Metabolism 84 4025-4030. (doi:10.1210/jc.84.11.4025)

Burger HG, Dudley EC, Robertson DM \& Dennerstein L 2002 Hormonal changes in the menopause transition. Recent Progress in Hormone Research 57 257-275. (doi:10.1210/rp.57.1.257)

Burger HG, Hale GE, Robertson DM \& Dennerstein L 2007 A review of hormonal changes during the menopausal transition: focus on findings from the Melbourne Women's Midlife Health Project. Human Reproduction Update 13 559-565. (doi:10.1093/humupd/ dmm020)

Cameron MD, Schmidt EE, Kerkvliet N, Nadkarni KV, Morris VL, Groom AC, Chambers AF \& MacDonald IC 2000 Temporal progression of metastasis in lung: cell survival, dormancy, and location dependence of metastatic inefficiency. Cancer Research $\mathbf{6 0}$ 2541-2546.

Cannon JG, Cortez-Cooper M, Meaders E, Stallings J, Haddow S, Kraj B, Sloan G \& Mulloy A 2010 Follicle-stimulating hormone, interleukin-1, and bone density in adult women. American Journal of Physiology: Regulatory, Integrative and Comparative Physiology 298 R790-R798. (doi:10.1152/ajpregu.00728.2009)

Chiovaro F, Martina E, Bottos A, Scherberich A, Hynes NE \& Chiquet-Ehrisman R 2015 Transcriptional regulation of tenascin-W by TGF-beta signaling in the bone metastatic niche of breast cancer cells. International Journal of Cancer 137 1842-1854. (doi:10.1002/ ijc.29565)

Coleman R, de Boer R, Eidtmann H, Llombart A, Davidson N, Neven P, von Minckwitz G, Sleeboom HP, Forbes J, Barrios C, et al. 2013 Zoledronic acid (zoledronate) for postmenopausal women with early breast cancer receiving adjuvant letrozole (ZO-FAST study): final 60-month results. Annals of Oncology 24 398-405. (doi:10.1093/ annonc/mds277)

Coleman R, Powles T, Paterson A, Gnant M, Anderson S, Diel I, Gralow J, von Minckwitz G, Moebus V, Bergh J, et al. 2015 Adjuvant bisphosphonate treatment in early breast cancer: meta-analyses of individual patient data from randomised trials. Lancet $\mathbf{3 8 6}$ 1353-1361. (doi:10.1016/S0140-6736(15)60908-4)

Coleman RE, Marshall H, Cameron D, Dodwell D, Burkinshaw R, Keane M, Gil M, Houston SJ, Grieve RJ, Barrett-Lee PJ, et al. 2011 Breast-cancer adjuvant therapy with zoledronic acid. New England Journal of Medicine 365 1396-1405. (doi:10.1056/ NEJMoa1105195)

Colleoni M, O'Neill A, Goldhirsch A, Gelber RD, Bonetti M, Thurlimann B, Price KN, Castiglione-Gertsch M, Coates AS, Lindtner J, et al. 2000 Identifying breast cancer patients at high risk for bone metastases. Journal of Clinical Oncology 18 3925-3935.

Cox TR, Rumney RM, Schoof EM, Perryman L, Hoye AM, Agrawal A, Bird D, Latif NA, Forrest H, Evans HR, et al. 2015 The hypoxic cancer secretome induces pre-metastatic bone lesions through lysyl oxidase. Nature 522 106-110. (doi:10.1038/nature14492)

Cross SS, Yang Z, Brown NJ, Balasubramanian SP, Evans CA, Woodward JK, Neville-Webbe HL, Lippitt JM, Reed MW, Coleman RE, et al. 2006 Osteoprotegerin (OPG) - a potential new role in the regulation of endothelial cell phenotype and tumour

Published by Bioscientifica Ltd. 
angiogenesis? International Journal of Cancer 118 1901-1908. (doi:10.1002/ijc.21606)

Drake MT, McCready LK, Hoey KA, Atkinson EJ \& Khosla S 2010 Effects of suppression of follicle-stimulating hormone secretion on bone resorption markers in postmenopausal women. Journal of Clinical Endocrinology and Metabolism 95 5063-5068. (doi:10.1210/ jc.2010-1103)

El-Haibi CP, Bell GW, Zhang J, Collmann AY, Wood D, Scherber CM, Csizmadia E, Mariani O, Zhu C, Campagne A, et al. 2012 Critical role for lysyl oxidase in mesenchymal stem cell-driven breast cancer malignancy. PNAS 109 17460-17465. (doi:10.1073/ pnas.1206653109)

Ghajar CM, Peinado H, Mori H, Matei IR, Evason KJ, Brazier H, Almeida D, Koller A, Hajjar KA, Stainier DY, et al. 2013 The perivascular niche regulates breast tumour dormancy. Nature Cell Biology 15 807-817. (doi:10.1038/ncb2767)

Gnant M, Mlineritsch B, Stoeger H, Luschin-Ebengreuth G, Heck D, Menzel C, Jakesz R, Seifert M, Hubalek M, Pristauz G, et al. 2011 Adjuvant endocrine therapy plus zoledronic acid in premenopausal women with early-stage breast cancer: 62-month follow-up from the ABCSG-12 randomised trial. Lancet Oncology 12 631-641. (doi:10.1016/S1470-2045(11)70122-X)

Gnant M, Pfeiler G, Dubsky PC, Hubalek M, Greil R, Jakesz R, Wette V, Balic M, Haslbauer F, Melbinger E, et al. 2015 Adjuvant denosumab in breast cancer (ABCSG-18): a multicentre, randomised, double-blind, placebo-controlled trial. Lancet 386 433-443. (doi:10.1016/S0140-6736(15)60995-3)

Harries M, Taylor A, Holmberg L, Agbaje O, Garmo H, Kabilan S \& Purushotham A 2014 Incidence of bone metastases and survival after a diagnosis of bone metastases in breast cancer patients. Cancer Epidemiology 38 427-434. (doi:10.1016/j.canep.2014.05.005)

Holen I 2016 The bone microenvironment - multiple players involved in cancer progression. Journal of Bone Oncology 5 87-89. (doi:10.1016/j.jbo.2016.05.004)

Holen I, Cross SS, Neville-Webbe HL, Cross NA, Balasubramanian SP, Croucher PI, Evans CA, Lippitt JM, Coleman RE \& Eaton CL 2005 Osteoprotegerin (OPG) expression by breast cancer cells in vitro and breast tumours in vivo - a role in tumour cell survival? Breast Cancer Research and Treatment 92 207-215. (doi:10.1007/s10549005-2419-8

Holen I, Walker M, Nutter F, Fowles A, Evans CA, Eaton CL \& Ottewell PD 2016 Oestrogen receptor positive breast cancer metastasis to bone: inhibition by targeting the bone microenvironment in vivo. Clinical and Experimental Metastasis 33 211-224. (doi:10.1007/s10585-015-9770-x)

Hughes R, Qian BZ, Rowan C, Muthana M, Keklikoglou I, Olson OC, Tazzyman S, Danson S, Addison C, Clemons M, et al. 2015 Perivascular M2 macrophages stimulate tumor relapse after chemotherapy. Cancer Research 75 3479-3491. (doi:10.1158/00085472.CAN-14-3587)

Jeruss JS, Santiago JY \& Woodruff TK 2003 Localization of activin and inhibin subunits, receptors and SMADs in the mouse mammary gland. Molecular and Cellular Endocrinology 203 185-196. (doi:10.1016/S0303-7207(02)00291-5)

Kang Y \& Pantel K 2013 Tumor cell dissemination: emerging biological insights from animal models and cancer patients. Cancer Cell $\mathbf{2 3}$ 573-581. (doi:10.1016/j.ccr.2013.04.017)

Kinder M, Chislock E, Bussard KM, Shuman L \& Mastro AM 2008 Metastatic breast cancer induces an osteoblast inflammatory response. Experimental Cell Research 314 173-183. (doi:10.1016/ j.yexcr.2007.09.021)

Klein NA, Houmard BS, Hansen KR, Woodruff TK, Sluss PM, Bremner WJ \& Soules MR 2004 Age-related analysis of inhibin A, inhibin $B$, and activin a relative to the intercycle monotropic follicle-stimulating hormone rise in normal ovulatory women.
Journal of Clinical Endocrinology and Metabolism 89 2977-2981. (doi:10.1210/jc.2003-031515)

Krassas GE \& Papadopoulou P 2001 Oestrogen action on bone cells Journal of Musculoskeletal and Neuronal Interactions 2 143-151.

Lam J, Takeshita S, Barker JE, Kanagawa O, Ross FP \& Teitelbaum SL 2000 TNF-alpha induces osteoclastogenesis by direct stimulation of macrophages exposed to permissive levels of RANK ligand. Journal of Clinical Investigation 106 1481-1488. (doi:10.1172/JCI11176)

Lim PK, Bliss SA, Patel SA, Taborga M, Dave MA, Gregory LA, Greco SJ, Bryan M, Patel PS \& Rameshwar P 2011 Gap junction-mediated import of microRNA from bone marrow stromal cells can elicit cell cycle quiescence in breast cancer cells. Cancer Research $\mathbf{7 1}$ 1550-1560. (doi:10.1158/0008-5472.CAN-10-2372)

Massague J \& Obenauf AC 2016 Metastatic colonization by circulating tumour cells. Nature 529 298-306. (doi:10.1038/nature17038)

Mastro AM, Gay CV \& Welch DR 2003 The skeleton as a unique environment for breast cancer cells. Clinical and Experimental Metastasis 20 275-284. (doi:10.1023/A:1022995403081)

Miyamoto K, Yoshida S, KawauumiI M, Hashimoto K, Kimura T, Sato Y, Kobayashi T, MiauchyI Y, Hoshi H, Iwaski R, et al. 2011 Osteoclasts are dispensable for hematopoietic stem cell maintenance and mobilization. Journal of Experimental Medicine 208 2175-2181. (doi:10.1084/jem.20101890)

Muller A, Homey B, Soto H, Ge N, Catron D, Buchanan ME, McClanahan T, Murphy E, Yuan W, Wagner SN, et al. 2001 Involvement of chemokine receptors in breast cancer metastasis. Nature 410 50-56. (doi:10.1038/35065016)

Nguyen DX, Bos PD \& Massague J 2009 Metastasis: from dissemination to organ-specific colonization. Nature Reviews Cancer 9 274-284. (doi:10.1038/nrc2622)

Orimo A, Gupta PB, Sgroi DC, Arenzana-Seisdedos F, Delaunay T, Naeem R, Carey VJ, Richardson AL \& Weinberg RA 2005 Stromal fibroblasts present in invasive human breast carcinomas promote tumor growth and angiogenesis through elevated SDF-1/CXCL12 secretion. Cell 121 335-348. (doi:10.1016/j.cell.2005.02.034)

Ottewell PD, Wang N, Brown HK, Fowles CA, Croucher PI, Eaton CL \& Holen I 2015 OPG-Fc inhibits ovariectomy-induced growth of disseminated breast cancer cells in bone. International Journal of Cancer 137 968-977. (doi:10.1002/ijc.29439)

Ottewell PD, Wang N, Brown HK, Reeves KJ, Fowles CA, Croucher PI, Eaton CL \& Holen I 2014 Zoledronic acid has differential antitumor activity in the pre- and postmenopausal bone microenvironment in vivo. Clinical Cancer Research 20 2922-2932. (doi:10.1158/10780432.CCR-13-1246)

Papayannopoulou T, Priestley GV, Nakamoto B, Zafiropoulos V \& Scott LM 2001 Molecular pathways in bone marrow homing: dominant role of alpha(4)beta(1) over beta(2)-integrins and selectins. Blood 98 2403-2411. (doi:10.1182/blood.V98.8.2403)

Park SI, Lee C, Sadler WD, Koh AJ, Jones J, Seo JW, Soki FN, Cho SW, Daignault SD \& McCauley LK 2013 Parathyroid hormone-related protein drives a CD11b+Gr1+ cell-mediated positive feedback loop to support prostate cancer growth. Cancer Research 73 6574-6583. (doi:10.1158/0008-5472.CAN-12-4692)

Paterson AH, Anderson SJ, Lembersky BC, Fehrenbacher L, Falkson CI, King KM, Weir LM, Brufsky AM, Dakhil S, Lad T, et al. 2012 Oral clodronate for adjuvant treatment of operable breast cancer (National Surgical Adjuvant Breast and Bowel Project protocol B-34): a multicentre, placebo-controlled, randomised trial. Lancet Oncology 13 734-742. (doi:10.1016/S1470-2045(12)70226-7)

Pelekanou V, Kampa M, Kiagiadaki F, Deli A, Theodoropoulos P, Agrogiannis G, Patsouris E, Tsapis A, Castanas E \& Notas G 2016 Estrogen anti-inflammatory activity on human monocytes is mediated through cross-talk between estrogen receptor ERalpha36 and GPR30/GPER1. Journal of Leukocyte Biology 99 333-347. (doi:10.1189/jlb.3A0914-430RR)
(C) 2016 Society for Endocrinology Printed in Great Britain
Published by Bioscientifica Ltd 
Pequeux C, Raymond-Letron I, Blacher S, Boudou F, Adlanmerini M, Fouque MJ, Rochaix P, Noel A, Foidart JM, Krust A, et al. 2012 Stromal estrogen receptor-alpha promotes tumor growth by normalizing an increased angiogenesis. Cancer Research $\mathbf{7 2}$ 3010-3019. (doi:10.1158/0008-5472.CAN-11-3768)

Perrien DS, Achenbach SJ, Bledsoe SE, Walser B, Suva LJ, Khosla S \& Gaddy D 2006 Bone turnover across the menopause transition: correlations with inhibins and follicle-stimulating hormone. Journal of Clinical Endocrinology and Metabolism 91 1848-1854. (doi:10.1210/ jc.2005-2423)

Png KJ, Halberg N, Yoshida M \& Tavazoie SF 2012 A microRNA regulon that mediates endothelial recruitment and metastasis by cancer cells. Nature 481 190-194. (doi:10.1038/nature10661)

Powles T, Paterson A, McCloskey E, Schein P, Scheffler B, Tidy A, Ashley S, Smith I, Ottestad L \& Kanis J 2006 Reduction in bone relapse and improved survival with oral clodronate for adjuvant treatment of operable breast cancer (ISRCTN83688026). Breast Cancer Research 8 R13. (doi:10.1186/bcr1384)

Qiu X, Yuan XG, Jin XL, He X, Zhu L \& Zhao XY 2012 Oestrogendeficiency inducing haematopoiesis dysfunction via reduction in haematopoietic stem cells and haematopoietic growth factors in rats. International Journal of Experimental Pathology 93 179-187. (doi:10.1111/j.1365-2613.2012.00815.x)

Roodman GD 2001 Biology of osteoclast activation in cancer. Journal of Clinical Oncology 19 3562-3571.

Seriwatanachai D, Thongchote K, Charoenphandhu N, Pandaranandaka J, Tudpor K, Teerapornpuntakit J, Suthiphongchai T \& Krishnamra N 2008 Prolactin directly enhances bone turnover by raising osteoblast-expressed receptor activator of nuclear factor kappaB ligand/osteoprotegerin ratio. Bone 42 535-546. (doi:10.1016/j.bone.2007.11.008)

Shaikh A, Bhartiya D, Kapoor S \& Nimkar H 2016 Delineating the effects of 5-fluorouracil and follicle-stimulating hormone on mouse bone marrow stem/progenitor cells. Stem Cell Research and Therapy $\mathbf{7}$ 59. (doi:10.1186/s13287-016-0311-6)

Shiozawa Y, Pedersen EA, Havens AM, Jung Y, Mishra A, Joseph J, Kim JK, Patel LR, Ying C, Ziegler AM, et al. 2011 Human prostate cancer metastases target the hematopoietic stem cell niche to establish footholds in mouse bone marrow. Journal of Clinical Investigation 121 1298-1312. (doi:10.1172/JCI43414)

Siraj A, Desestret V, Antoine M, Fromont G, Huerre M, Sanson M, Camparo P, Pichon C, Planeix F, Gonin J, et al. 2013 Expression of follicle-stimulating hormone receptor by the vascular endothelium in tumor metastases. BMC Cancer 13 246. (doi:10.1186/1471-2407-13-246)

Smid M, Wang Y, Klijn JG, Sieuwerts AM, Zhang Y, Atkins D, Martens JW \& Foekens JA 2006 Genes associated with breast cancer metastatic to bone. Journal of Clinical Oncology 24 2261-2267. (doi:10.1200/JCO.2005.03.8802)

Sutherland A, Forsyth A, Cong Y, Grant L, Juan TH, Leejk Klimowicz A, Petrillo SK, Hu J, Chan A, et al. 2015 The role of prolactin in bone metastasis and breast cancer cell-mediated osteoclast differentiation. Journal of the National Cancer Institute 108 djv338. (doi:10.1093/jnci/ djv338)

Tanner MJ, Hadlow NC \& Wardrop R 2011 Variation of female prolactin levels with menopausal status and phase of menstrual cycle. Australian and New Zealand Journal of Obstetrics and Gynaecology $\mathbf{5 1}$ 321-324. (doi:10.1111/j.1479-828X.2011.01321.x)

Vivacqua A, De Marco P, Santolla MF, Cirillo F, Pellegrino M, Panno ML, Abonante S \& Maggiolini M 2015 Estrogenic gper signaling regulates mir144 expression in cancer cells and cancer-associated fibroblasts (cafs). Oncotarget 6 16573-16587. (doi:10.18632/oncotarget.4117)

Wang H, YuU C, Gao X, Welte T, MuscarellaAM, Tian L, Zhao H, Zhao Z, Dus, Tao J, et al. 2015 The osteogenic niche promotes early-stage bone colonization of disseminated breast cancer cells. Cancer Cell 27 193-210. (doi:10.1016/j.ccell.2014.11.017)

Wang Z, Xiong S, Mao Y, Chen M, Ma X, Zhou X, Ma Z, Liu F, Huang Z, Luo Q, et al. 2016 Periostin promotes immunosuppressive premetastatic niche formation to facilitate breast tumour metastasis. Journal of Pathology 239 484-495. (doi:10.1002/path.4747)

Westbrook JA, Cairns DA, Peng J, Speirs V, Hanby AM, Holen I, Wood SL, Ottewell PD, Marshall H, Banks RE, et al. 2016 CAPG and GIPC1: breast cancer biomarkers for bone metastasis development and treatment. Journal of the National Cancer Institute 108 djv360. (doi:10.1093/jnci/djv360)

Wilson C, Holen I \& Coleman RE 2012 Seed, soil and secreted hormones: potential interactions of breast cancer cells with their endocrine/paracrine microenvironment and implications for treatment with bisphosphonates. Cancer Treatment Reviews $\mathbf{3 8}$ 877-889. (doi:10.1016/j.ctrv.2012.02.007)

Wilson C, Coleman RE, Nutter F, Brown HK \& Holen I 2016 Effects of the female hormone inhibin - a in vivo; potential contribution to the antitumour effects of zoledronic acid. Bone (doi:10.1530/ boneabs.5.p105)

Yan X \& Ye TW 2015 Early molecular responses of bone to estrogen deficiency induced by ovariectomy in rats. International Journal of Clinical and Experimental Medicine 8 5470-5477.

Zhu LL, Blair H, Cao J, Yuen T, Latif R, Guo L, Tourkova IL, Li J, Davies TF, Sun L, et al. 2012 Blocking antibody to the beta-subunit of FSH prevents bone loss by inhibiting bone resorption and stimulating bone synthesis. PNAS 109 14574-14579. (doi:10.1073/ pnas.1212806109)

Received in final form 16 September 2016

Accepted 29 September 2016

Accepted Preprint published online 29 September 2016
(C) 2016 Society for Endocrinology Printed in Great Britain
Published by Bioscientifica Ltd 